\title{
Relativism, Contextualism, and Temporal Perspective
}

\author{
Relativismo, Contextualismo y perspectivas sobre el tiempo
}

\begin{abstract}
This article argues that there is no such thing as a proposition with variable truth-values, at least when considering English tensed sentences. This means that any account of meaning and truth that appeals to a notion of proposition with different truth-values at different times is necessarily at fault. The reason is that any evaluation context is always dominated by a temporal perspective beyond both speaker and audience and embedded to the communicational common ground. Only an approach that takes this into consideration is successful.
\end{abstract}

Keywords: proposition, use, assessment, speaker's point of view, time.

\author{
JUAN J. COLOMINA ALMIÑANA*
}

\begin{abstract}
Resumen: Este artículo defiende que ninguna proposición puede tener un valor de verdad variable. Ello quiere decir que cualquier aproximación al significado y la verdad que tiene por base una noción de proposición con valor de verdad variable nunca puede llevar razón. El principal motivo es que todo contexto de evaluación para dichos valores de verdad siempre estará dominado por una perspectiva temporal (dependiente del trasfondo comunicativo que hablante y audiencia comparten) y tan sólo una explicación que tenga en cuenta dicho fenómeno puede proporcionar una solución viable al problema del aparente cambio de valor de verdad de algunas de las oraciones de nuestros lenguajes naturales.
\end{abstract}

Palabras clave: proposición, uso, evaluación, punto de vista del hablante, tiempo.

\footnotetext{
"Sentences are not as such either true or false" (Austin 1962: 111).

"A sentence is made up of words, a statement is made in words... Statements are made, words or sentences are used" (Austin 1979: 120).
}

There is a tradition that argues that tensed sentences have changing truth-values. According to such tradition, a certain proposition may have different truth-values at different times. In other words, the truth-values of certain sentences including some temporal reference

Recibido: 29/06/2018. Aceptado: 21/10/2018.

* The University of Texas at Austin. Contact: colomina-alminana_juan@austin.utexas.edu. His most recent publications are "Pragmatic Presupposition and Unarticulated Constituents", Lingua 206: 112-126 and Formal Approach to the Metaphysics of Perspectives (Springer, 2018). 
(those sentences which include tense or any other meta-linguistic temporal variable) should be considered a function of parameters determined by a context of use and a context of evaluation. This kind of account, although capable of fine-graining certain circumstances of assessment that resist other proposals, however cannot explain some basic facticity of time. For instance, some elements involved in such assessment are embedded in the context of evaluation itself, so sentence-truth is relativized to the context of evaluation but does not necessarily respond to the context of use, since the dimension of evaluation of the later is something else other than truth.

Consider the quintessential example:

(1) There will be a sea-battle tomorrow.

In order to properly account for the truth of (1), some believe that one needs to relativize utterance-truth to a context of assessment (the judge's parameter, something like a subjective standard to contrast with the sentence's content), and sentence-truth to both a context of utterance (which would include the time when the sentence is uttered) and the context of assessment (MacFarlane 2003). In this case, when one asserts (1), the truth-value of such an utterance (the specific sentence-token) is embedded in the context of evaluation of that concrete instance where the sentence has been uttered, but the truth of the sentence itself (the sentence-type) must be relative to a double-indexing that accounts for both, the concrete time the sentence is uttered and the concrete standards of evaluation at hand when such sentence is uttered. However, as Brogaard (2008) and many others have pointed out, such circumstances of assessment have certain objective features which simply cannot change under any intensional operator, which actually invalidates the relativist's own expectations. Furthermore, such features actually depend upon some normative conditions that would indicate whether such a sentence is or not successful, but not necessarily true or false, since these conditions have to do with the proper employment of the sentence in question.

This article offers an alternative to such a relativistic account. It approaches the same data as relativism but arguing that there is no such thing as truth-value shifting sentences. The idea behind this claim is two-fold. First, the statements through the use of sentences, and not sentences themselves, are what can be either true or false. Second, the statement's truth-values cannot change because they are determined by truth-conditions. The difference between any relativist and contextualist solution and the proposed here is that my account considers how only under a certain normative perspective one can approach the truth of any statement. Such a perspective always includes objective temporal coordinates, which are beyond speaker and audience, and are embedded in the communicational common ground. Therefore, to properly approach to the truth of any statement, one first has to figure out which perspective the sentence employed to make it belongs.

The plan of the article is as follows. In the three first sections, I review the preferred theories about temporal sentences that precede current debates about relativism and contextualism, critically analyzing their flaws and highlighting their strengths. In the fourth section, I introduce my alternate account. It demonstrates that a temporal point of view dominates over all subordinate clauses. This temporal point of view is beyond both 
speaker and audience, and it is embedded in the communicational common ground that both share. Therefore, any context of evaluation would always be subordinated to such temporal perspective as well, and whichever truth-conditional determination it comes with.

\section{Presentism and tensed sentences}

One classical approach to tensed sentences is that developed by Arthur Prior in the 1950s-1960s. Prior advocates for a presentist theory that considers time as a logical construction from tensed propositions. According to Prior's account, a sentence such as

(2) I am eating my breakfast

in an instance such that

(3) It was the case that I am eating my breakfast

is nothing other than a propositional variable $p$ which may have different truth-values at different times depending to which time such a variable refers (Prior 1957: 8; Prior 1967: 14-16; Prior 1968: 8). This is to say, for Prior, all sentences are evaluated relative to a time, and all sentences can only be true or false relative to some time or other. However, the explicit mention of time occurs only at the level of the metalanguage, and never in the object language. ${ }^{1}$

In fact, Prior (1967: 14) states that:

For in English sentences, the point of view of the speaker dominates even subordinate clauses. When an English speaker, for example, wants to say on Tuesday that someone complained on Monday of a sickness that he had that day, the correct form of words will be "He said he was sick," although the man was in fact complaining not of a then-past but a then-present sickness, and his own words would have been "I am sick."

It is clear that, in natural language, tenses appear to be devices one can employ to make reference to time without making explicit mention of any time in particular. Prior's theory is the perfect example of a certain way of displaying the concrete mechanism of reference for indexical expressions. For Prior then, English is an object language in which tense operators are constructed as analogues of sentential modal operators in the meta-language. ${ }^{2}$

1 Given Prior's analysis of past and future tensed sentences as $\mathrm{P} p$ and F $p$ respectively, and where $\mathrm{P} p$ is true at $t$ iff is true at $t^{\prime}$, for some $t^{\prime}$ earlier than $t$, and $\mathrm{F} p$ is true at $t$ iff is true at $t^{\prime}$, for some $t^{\prime}$ later than $t$.

2 Prior's redundant theory of the present tense actually understands the proposition "It is now the case that $p$ " as the very same proposition that $p$. Hence, Prior considers that the present tense is the understood tense of any tensed proposition, so there is no need for any other operator for "now". The reason behind this is Prior's metaphysical theory of time. According to Prior, only the present time exists, and both past and future are constructs from the present moment, being the former fixed (because it has already occurred) and the later open (since it is still to come). 
However, in spite of the advantages that Prior's theory has, it cannot explain sentences making explicit reference to a time, since such sentences cannot be true or false relative to any time at all, but they must be true or false in reference to such a determined moment in time. In order to prevent this system from failing, Kamp amended Prior's theory to include a now operator ' $\mathrm{N}$ ' (in a Montagovian semantics) to save the idea of propositions with variable truth-value. According to Kamp (1972), any sentence referring to the present moment will be true if and only if it is true at the present moment, relativizing that sentence's truth-values to the contextuality of the present moment. ${ }^{3}$ However, Kamp's system has the same problems than Prior's, since the variability of time still lets some sentences have shifting truth-values depending upon the concrete time to which the variable at hand refers.

A further attempt to amend Prior's system includes the attitudes of the speaker in the determination of the sentences' truth-values. In this fashion, Needham (1976) introduces another 'now' operator, an explicit indicator of the present tense, since according to him it is necessary to introduce such an operator in tensed contexts where we have quantification over items other than moments (see also Needham 1975). In this renewed system, 'now' picks out a definite time just as a date does. According to this system then, a sentence such as

(4) Some day, all those who took part in the plot will be brought to justice translates as

(5) $\mathrm{N}^{\alpha}{ }^{\alpha} \mathrm{F}^{\beta} \forall \chi\left({ }^{\alpha} \mathrm{P}^{\gamma \gamma} \phi \chi \supset^{\beta} \Psi \chi\right)$

In other words, the point of view of the speaker dominates all subordinate contexts. The division of time into past, present, and future is dependent of the concrete speaker's point of view at the time of utterance of any sentence, which will remain the same in all subordinate contexts where the speaker is involved. Hence, although the past tense in the antecedent of (4) occurs within the scope of a future tense operator, it nevertheless takes us to some moment earlier than the present rather than to some moment earlier than future time.

This is, of course, in direct opposition to Prior's view, where it is possible to iterate tense operators generating structures like 'the future past,' 'the past future present,' and so forth. However, Needham argues, it is not possible to iterate expressions which indicate pastness, presentness, and futurity since it does not seem possible "to formulate complex tense structures without also taking account of the serial order of time explicitly" (1976: 316). In other words, Needham sides with Reichenbach (1958) when considering that the time-reference points preclude iteration:

Any formula containing one or more occurrences of the 'now-operator' not taking the whole sentence as their scope, and binding one or more distinct variables, is logically equivalent to a formula (which appropriate change of variables to avoid clashes) in which the operator does have the greatest possible scope. (Needham 1976: 317)

3 In formal terms, $\mathrm{N} \varphi$ is true at $t$ iff $\varphi$ is true at $n$. 
As we have seen, Needham's main idea is then that any sentence's tense is actually a date (or behaves like a date does) determined by the moment when a speaker utters a sentence, and which links its occurrence to such a concrete time in particular. Therefore, any sentence must be understood as an occasion sentence anchored to the concrete time the speaker utters such a sentence. One problem with this position though is to understand the claim in terms of eternal sentences: Is any occasion sentence to be understood as a type-sentence, or should one understand an occasion sentence as a token-sentence? To me, Needham's approach is mistaken if sentences are understood in invariant terms as embedded to the point of view of the speaker, for this will mean that the same sentence will have settle its truth-conditions relative to such a speaker even before any use. In other words, if the speaker's point of view will determine the time of reference for any utterance, then it is not possible to say that such determination occurs with independence of the actual bearer of such a point of view. However, if this is the case, what Needham really means by sentence is actually the concrete occasional use of a sentence by a specific speaker in a specific time. Therefore, Needham is actually speaking about utterance-truth and not sentence-truth. Under this standard though, Needham is not in better conditions that Prior and Kamp when they stated that only relative to the time of utterance a sentence can be assessed, since a sentence's truth-value will still shift depending upon who and when one actually utters such a sentence.

Think of the following example:

\section{(6) I am thirsty (now).}

This sentence type, according to Prior, has different truth-values depending on when one utters it. For Needham, this is simply wrong because the correct way to interpret (6) is by referring to a time variable embedding the concrete date of the utterance to a speaker on a certain occasion -the present moment in this case. The key for Needham is then to understand (6) as a tenseless sentence, and the concrete occasions of utterance of such as sentence are what have actually a tense/date. Needham compares this with the moment when one writes a letter. If one writes now in a letter "It's raining," this means that is raining at the time that she is writing the letter. When one receives the letter, that person will learn that it was raining at the time she wrote the letter, since the time when she wrote the letter binds to the sentence. ${ }^{4}$

A priori, this seems sound. However, it is still problematic. The reason is that 'now' refers to the moment of speaking (or writing), no matter how deeply embedded in a sentence, which is actually independent of the speaker/writer. Since this time is different on any two occasions of speaking, one cannot employ the same sentence (6) as part of another sentence employed at a later time to report the same state of affairs that would have been reported when (6) could have been used to make a true statement. And the same holds for the case of the letter. For there is an objective temporal perspective independent

4 There is actually a whole contextualist tradition based on the seminal work by David Kaplan that analyzes this kind of example from a two-dimensional semantics framework. However, this tradition has problems explaining precisely this kind of example regarding recorded notes. See Section 2 for further details. 
of any speaker and content that actually dominates any speaker's point of view. In other words, if the time of a sentence is actually determined by the speaker's temporal position when uttering it, then it is difficult to see how such link actually occurs beyond that concrete speaker and that particular moment of time.

\section{Kaplanian character and contextualism}

A different approach to the previous problematic is pursued by Kaplan, Lewis, and others. As initially advocated, they developed a framework in a two-dimensional semantic analysis in order to correctly represent the different ways in which the truth-values of the sentences in our natural language depend on the concrete context of their utterance.

Specifically, Kaplan (1989) proposed a two-step derivation about meaning. This view establishes that the truth-conditions of sentences depend upon what he called their character (a function that relates a context to a content) and their content (as a function from world-time pairs $\langle\mathrm{w}, \mathrm{t}\rangle$ to truth-values $\{0,1\}) .{ }^{5}$ According to this framework, the semantically basic two-dimensional relation is that of sentence $s$ being true at context $c$ at index $i$, where a context is a concrete location that centers the sentence (this is to say, the time, the place and the possible world that the concrete sentence is talking about, or centered world), and an index is the $n$-tuple set of features of this particular context (for instance, a concrete speaker and a concrete audience). In all particular contexts $c$, we can find the concrete index $i$ for this particular context, or $i_{c}$, where the mentioned index provides the correct co-ordinates, demonstrating appropriate features that define $c$. In formal terms, sentence $s$ is true at context $c$ if and only if $s$ is true at context $c$ at index $i_{c}$ (Lewis 1980). ${ }^{6}$

However, this account cannot explain, as is, the evident truth of certain cases involving explicit indexical temporal terms. Think, for instance, about

(7) I am here now.

Following Kaplan's two-dimensional semantics, the previous sentence would be true if and only if the speaker is in the place of utterance at the moment of utter it, what implies that such a sentence is analytically true (Predelli 2011), since virtually the sentence would be true whenever uttered. However, the same logic should apply to its negation,

5 To me, Mott's (1973) semantic analysis of Prior's 'T' operator could be understood as a precedent of Kaplan's theory. Mott's re-interpretation is as follow:

(5) T $m \varphi$ is true at $t$ iff $\varphi$ is true at the time designated by $m$.

Since the time at which $\operatorname{T} m \varphi$ is evaluated on the left hand of the equivalence is irrelevant to the right hand, Mott (1973: 79) concludes that if Tm $\varphi$ is true at any time, it must be true at all times. However, this is not correct since every proposition seems to be evaluated at exactly one time, including those sentences which time is explicit.

6 Besides the fact that Lewis' and Kaplan's theories are based on possible worlds, both are actually different. Kaplan's analysis accepts possible worlds as epistemological/logical possibilities (like Kripke did) whereas Lewis considers them as material possibilities. Both options have their own insights and problems, but this article shall only focus on Kaplan's approach. 
(8) I am not here now.

In Kaplan's framework, (8) would be true only if the speaker is in the place of utterance when uttering it, which is contradictory. Hence, (8) must always be false, which obviously violates the basic intuitions we have regarding some instances of such a sentence, like for example when one writes (8) on a post-it and leaves it attached to her office door, or when one listens to it as a recorded message left on somebody's answering machine or voice mail.

The preferred solution to this problem, as stated by Predelli (1998), is that sentences in recorded messages and written notes are to be evaluated with respect to the intended context of interpretation, which need not coincide with the context of utterance. In example (8) as recorded or written then, besides the fact that the context of utterance determines who is the speaker, and where and when the utterance takes place, one should interpret it as being intentionally uttered (recorded or written) for a posterior moment (the moment of listening or reading it) and not as embedded in the concrete time of utterance when recorded or written. Furthermore, there is no requirement for the speaker to be anywhere near to the location of utterance at the time of uttering it, but only that the speaker has some expectation that her utterance will be assessed keeping in mind the original time when the utterance took place. ${ }^{7}$

In spite of its apparent soundness, this solution is still mistaken. The reason is that even though one could agree that it is better to re-locate the time of utterance in a moment in the future when the sentence is actually heard or read, this cannot be the sole product of an intentional movement by the speaker, since it is not up to the speaker to determine what is the past, the present, and the future. One has the intuition that these moments are independent of the speaker and even the audience, and that their existence should depend upon semantic reference. (In fact, this case is similar to this other. Consider somebody that believes the name "Aristotle" (as occurs in a sentence such a "Aristotle is Greek") only designates Aristotle at the time he lived. This obviously supposes confusion between designation and denotation, since although it is true that nobody could now designate to Aristotle in the present time, the name "Aristotle" still denotes Aristotle.)

\section{Relativism and the shifting truth-value}

Following Kaplan's two-dimensional framework, some relativists have argued that some sentences, including temporal sentences, even though referring to the same content across contexts, shift their truth-values not only according to where and/or when a sentence is uttered, but also according to who utters it. This is to say, there are sentences which truth-values change according to individual subjective judgments. These authors introduce

7 In an important sense, Predelli's solution to the paradoxical appearance of recorded messages resembles Needham's solution to truth-variability of occasion sentences. Predelli appeals to an intentional movement from the speaker that re-centers the context from the context of utterance to the context of interpretation whereas Needham prefers to reduce any context to that determined by the speaker's point of view. In the end, as Plumer (1988) states, perhaps this distinction is already captured by the differences existing between the phenomenon of the speaker's reference as opposed to semantic reference. 
a new judge-index in order to evaluate such sentences. The value of this new parameter is provided by the derivation of truth-value from content, but never by the derivation of content from character (Lasershon 2005: 643). In other words, truth-value for the different judgments is relative to the pragmatic context established from the world-time-judge triple $<\mathrm{w}, \mathrm{t}, \mathrm{j}>$. Therefore, a sentence can be true for one speaker relative to $w$ at $t$ but false for another speaker relative to the same $w$ at same $t$. Thus, every time that a speaker utters a sentence, it will be evaluated according to the particular pragmatic context in which such utterance is made. This is clear for the so-called predicates of personal taste, situations where supposed contrary sentences about personal opinions occur without contradiction, as showed in Colomina-Alminana (2015). Suppose one utters

(9) $x$ is delicious.

In semantic terms, one can translate (9) as follows:

(10) $\|$ delicious $\| \mathrm{c} ; \mathrm{w}, \mathrm{t}, \mathrm{j}=[\lambda x \mathrm{e} \cdot \mathrm{x}$ tastes delicious for $\mathrm{j}$ in $\mathrm{w}$ at $\mathrm{t}]$

Stephenson (2007) further develops Lasersohn's account. She claims that these predicates of personal assessment actually are two-place predicates, in which PRO is taken as the second argument substituting the judge. In her words,

(11) $\|$ delicious $\| \mathrm{c} ; \mathrm{w}, \mathrm{t}, \mathrm{j}=[\lambda x \mathrm{e} . x$ tastes delicious for $\mathrm{j}$ in $\mathrm{w}$ at $\mathrm{t}]$

should be understood as

(12) $\|P R O j\| c ; w, t, j=j$

resulting in at least the following three different scenarios

(13) a. $\|$ The $x$ tastes delicious PROj\| $\mathrm{c} ; \mathrm{w}, \mathrm{t}, \mathrm{j}=$ true if and only if the $x$ tastes delicious for $\mathrm{j}$ in $\mathrm{w}$ at $\mathrm{t}$

b. \|The $x$ tastes delicious PROJames $\| \mathrm{c} ; \mathrm{w}, \mathrm{t}, \mathrm{j}=$ true if and only if the $x$ tastes delicious for James in $\mathrm{w}$ at $\mathrm{t}$

c. $\|$ The $x$ tastes delicious for James $\| \mathrm{c} ; \mathrm{w}, \mathrm{t}, \mathrm{j}=$ true if and only if the $x$ tastes delicious for James in $\mathrm{w}$ at $\mathrm{t}$

The essential difference between both approaches is that Lasersohn treats the operator 'delicious for' as a modifier of the predicate 'delicious,' while Stephenson considers it an argument for the same predicate (Stephenson 2007: 520). According to Stephenson then, only the interpretation (13.a) is really judge-dependent. The other two interpretations depend upon either a linguistic context (13.b) or a pragmatic context (13.c), and neither of them for her actually provides the adequate value of the judge argument for the sentence. According to this view, it seems that sentences with predicates of personal taste are judgedependent only if they take PROj as an argument. This is to say, when they include some 
subjective meaning. Otherwise, their truth-values could not shift because they would be embedded in either semantic or conventional normative scenarios (Stephenson 2007: 500).

MacFarlane (2003) analyzes future contingents in a similar fashion that others have treated predicates of personal taste. According to MarFarlane, in order to properly account for the truth of sentences including tenses such as (1), one needs to relativize utterance-truth to a context of assessment (the judge's parameter pointed out before), and sentence-truth to both a context of utterance (in a Kaplanian fashion, which will center the speaker, the time, and place in which the sentence is uttered) and the previous context of assessment (MacFarlane 2003). In this case, when one asserts (1) then, the truth-value of such utterance (the specific sentence-token) should be understood as embedded in the context of evaluation for that concrete instance, where the sentence has been uttered, but the truth of the sentence itself (the sentence-type) must be relative to a double-indexing that accounts for both, the concrete time the sentence is uttered and the concrete standards of evaluation at hand when such sentence is uttered. MacFarlane (2009) calls this approach non-indexical contextualism.

In this account, the propositional content expressed by a sentence would be the same in every possible judgment scenario. However, such sentence would take different truthvalues in any of the different judgment scenarios under scrutiny. In other words, for MacFarlane the truth-values of a temporal sentence such as (1) depend on the judge's perspective of whom utters it, which actually relativizes a sentence's truth-values besides accepting the same sentence's content. As shown, when evaluating truth-utterance as relative, MacFarlane (2005) suggests going beyond a two-dimensional framework for correctly discerning the truth-value of sentences including temporal elements such as tense. Because a sentence $s$ at a context $c$ at an index $i_{c}$ could be true from a certain judgment but false from another, these judgments are thought to share similar contexts, but actually represent different locations depending on where a concrete sentence is valued. In other words, we have a relativistic position that values differently the same sentence $s$ in the centered context $c$ defined by $i_{c}$ depending on the judgment where we apply it. Consequently, sentences' truth-values depend again upon a speaker's point of view that will dominate any semantic or conventional context.

However, this position is highly problematic. If one considers, as MacFarlane does, that the same sentence can have different truth-values depending on the fact that it is uttered by different speakers under different judge's parameters, then we have to accept that either the sentences are actually contradictory (since apply different truth-values to the same state of affairs), or they actually refer to different state of affairs. Since MacFarlane is explicit about the fact that the sentence's content is the same for both occasion sentences, but the speaker's judgment actually represents different locations depending on where a concrete sentence is valued, we must then agree that under MacFarlane's framework two occasions of the same sentence cannot have shifting truth-values since they actually refer to different scenarios.

The key to understand why is provided by Goodman (1978). Goodman asserts that conflicting true sentences must correspond to different versions of the world, and such true sentences then express different truths about those different versions. Think for instance about the two sentences below (the example is from Goodman 1978: 112): 
(14) The kings of Sparta had two votes.

(15) The kings of Sparta had only one vote.

According to Goodman, the previous sentences, understood to describe the same world, must be contradictory. However, Goodman claims, those sentences are not describing the same world, but actually are part of different world versions: different descriptions of how the world might be. In fact, Goodman clarifies, we should understand the previous sentences as referring to different version of the world:

(14') According to Herodotus, the kings of Sparta had two votes.

(15') According to Thucydides, the kings of Sparta had only one vote.

Since both sentences express different truths, one is tempted to claim that one must be at fault and the other speaks truly. However, Goodman specifies, this is wrong, since in the end none of the sentences are saying anything at all regarding Sparta and the world itself, but actually about what both Herodotus and Thucydides said in regard to Sparta and the world. If this is true, then both sentences are about two different worlds. If one wants, both sentences may even state straight forward plain truths about a certain world, but with the inconvenience that the world cannot be the same for both sentences. Therefore, according to Goodman, we actually can have true contradiction between contrary sentences but, since there is no other way to solve such a conflict, one must accept that these sentences must refer to different interpretations of the world.

\section{Temporal perspective and truth}

In the previous sections I have demonstrated that there is no such a thing as a truth-value shifting sentence. The main reasons have to do with the fact that any contrary sentences regarding the same state of affairs would be contradictory. If they are not, then they cannot be about the same state of affairs. Furthermore, no account that actually appeals to a speaker's point of view would be successful in explaining the apparent phenomenon of the existence of a sentence with variable truth-values. These approaches actually consider subjective relativist engagement with the sentence's content, which actually makes such a sentence's truth judge-dependent. In the end, as the article has proven, these accounts side with the mistaken idea that our semantics can actually guide our ontology, which is at odds with the fact that true sentences state what is actually the case.

However, there is still a strong intuition in regard to the fact that some sentences of our natural language seem to have different truth-values depending on the moment that one utters them. Think, for instance, of whales. One can now truly assert

(16) Whales are mammals.

However, there was a time when one could assert without fault that

(17) Whales are not mammals. 
If this is actually correct, the question now is: Who is then at fault? One is inclined to say that, on the one hand, it seems that there are two different meanings of 'whale,' one in which whales are mammals and other in which they are not. If this is the case, the difference between both meanings seems to be merely verbal, to rely only on the use of the two different concepts of 'whale.' However, the dispute between the two meanings seems to go beyond mere discrepancy in usage. The difference seems to be substantive, and not merely verbal. This appeals to the normative status of what counts as 'whale.' This is, about the existence of some intrinsic characteristics in conventional more than semantic terms that distinguish what is a whale from what is something else. On the other hand, suppose that the meaning of the term 'whale' is the same for ancients and moderns. If this is the case, we have to agree that the ancient was wrong when considering whales are fish and not mammals, since it is now scientifically proven that whales are mammals. However, given the fact that many of the characteristics that define things are opaque to speakers, it may be the case that the ancient was simply unaware of what makes of whales different from fish, what counts as such, and then to be mistaken when considering a fish what in reality is a mammal. Hence, what a priori seemed a false assertion would merely be an error, which has been corrected by pointing out the proper characteristics that allow classifying whales as mammals and not as fish. In other words, both sentences belong to different temporal perspectives. Each temporal perspective establishes different truth-conditions for testing each statement/assertion one can make from within it, and will dominate over any further context.

The same holds for sentences such as (1). When one utters "there will be a sea-battle tomorrow," she is making a statement taking under consideration now the different open possibilities that could determine such sentence's truth-values. It would not be until the concrete temporal perspective settles that one can actually be aware of the conditions that apply and determine the truth or falsehood of such sentence. Therefore, when one says that whales are fish and not mammals, or that there will be a sea-battle tomorrow, such a statement must be contrasted with the truth-conditions established by the temporal perspective dominating the structural conditions that one inhabits. Those shall actually determine whether whales belong to the category of fish or to the category of mammals, and if actually there is a sea-battle. In other words, there is a common ground beyond both speaker and audience that they inhabit and determines the truth-conditions that contrast any statement/assertion made within such a perspective, and which refer to concrete state of affairs. These would be something similar to what Massimi (2018) calls standards of performance-adequacy. ${ }^{8}$ These standards of performance-adequacy actually are normative pragmatic and conventional testings that any sentence should pass to be satisfactory, and which would become of the statement made with such a sentence true or false.

Moreover, it is then the modification/negotiation of such common ground, the change of such standards, what explains the apparent variability of some sentence's truth-value. As shown, some sentences may be contrary but not contradictory, since in the end they refer to different conditions regarding the same state of affairs: those established by the

8 Rosenberg (2002) introduces standards of performance-adequacy to defend a perspectival theory of epistemic justification. Differently, Massimi (2018: 354) believes that such performance adequacy "must be met by scientific claims for them to be retained across scientific perspectives, i. e. for their ongoing performance to be judged as adequate by practitioners of different scientific perspectives." 
two different temporal perspectives to which the two sentences respectively belong. Therefore, there is not real change in truth-value, but actually one must agree that there are actually two different sentences, since the modification of the common ground that opens new truth-conditions allows for the creation of new statements. In other words, the state of affairs under discussion does not change, but actually our point of view about what is the case, and this is what is reflected by the use of the two different sentences on different occasions to refer to the same state of affairs. In the end, it seems intuitive that an adequate theory about temporal reference leaves some room for obtaining a relation between two propositions just in case one reports the same state of affairs as the other but from a different point of view. This is what temporal perspectives capture and is, after all, a general feature of tenses. ${ }^{9}$

\section{References}

Austin, John L. (1962), Sense and sensibilia, Oxford: Oxford University Press.

Austin, John L. (1979), Philosophical papers ( $3^{\text {rd }}$ edition), Oxford: Oxford University Press. Brogaard, Berit (2008), «In defence of a perspectival semantics for 'know'», Australasian Journal of Philosophy, vol. 86, no. 3, pp. 439-459.

Colomina-Alminana, Juan (2015), «Disagreements and the speaker's point of view», Language and Dialogue, vol. 5, no. 2, pp. 224-246.

Goodman, Nelson (1979), Ways of worldmaking, New York: Hackett.

Kamp, Hans (1972), «Formal properties of 'now'», Theoria, vol. 32, no. 2, pp. 227-273.

Kaplan, David (1989), «Demonstratives», en: John Almog, John Perry y Howard Wetsttein (eds.): Themes from Kaplan, Oxford: Oxford University Press, pp. 481-565.

Lasersohn, Peter (2005), «Context dependence, disagreement, and predicates of personal taste», Linguistics and Philosophy, vol. 28, no. 6, pp. 643-686.

Lewis, David (1980), «Index, context, and content», en: Papers in Philosophical Logic, Cambridge: Cambridge University Press, pp. 21-44.

MacFarlane, John (2003), «Future Contingents and Relative Truth», The Philosophical Quarterly, vol. 53, no. 212, pp. 321-336.

MacFarlane, John (2005), «Making Sense of Relative Truth», Proceedings of the Aristotelian Society, vol. 105, no. 2, pp. 305-323.

MacFarlane, John (2009), «Non-indexical contextualism», Synthese, vol. 166, no. 2, pp. 231-250.

Massini, Michaela (2018), «Four kinds of perspectival truth», Philosophy and Phenomenological Research, vol. 96, no. 2, pp. 342-359.

Mott, Peter (1973), «Dates, tenseless verbs and token-reflexivity», Mind, vol. 82, no. 325, pp. 73-85.

Needham, Paul (1975), Temporal perspective: A logical analysis of temporal reference in English, Uppsala: Philosophical Studies, vol. 25.

9 Many thanks to Nicole M. Guidotti-Hernández for her comments on previous versions of this paper. This article is part of the project "Points of View, Dispositions and Time" (FFI2014-57409-R), funded by the Spanish Ministerio de Economía y Competitividad. 
Needham, Paul (1976), «The speaker's point of view», Synthese, vol. 32, no. 3/4, pp. 309-327. Plumer, Gilbert (1988), «Kaplan rigidity, time, and modality», Logique et Analyse, vol. 31, no. $123 / 124$, pp. 329-335.

Predelli, Stefano (1998), «I am not here now», Analysis, vol. 58, no. 2, pp. 107-115.

Predelli, Stefano (2011), «I am still not here now», Erkenntnis, vol. 74, no. 3, pp. 289-303.

Prior, Arthur (1957), Time and modality, Oxford: Oxford University Press.

Prior, Arthur (1967), Past, present and future, Oxford: Oxford University Press.

Prior, Arthur (1968), Papers on past and tense, Oxford: Oxford University Press.

Reichenbach, Hans (1958), The philosophy of space and time, New York: Dover.

Rosenberg, Jay (2002), Thinking about knowing, Oxford: Oxford University Press

Stephenson, Tamina (2007), «Judge dependence, epistemic modals, and predicates of personal taste», Linguistics and Philosophy, vol. 30, no. 4, pp. 487-525. 
